\title{
Altered coronary artery calcium scores before bariatric surgery
}

Patricia S Gadelha1*, Josemberg M Campos², Fernando Moraes², Mariana da F S Leão ${ }^{3}$ and Álvaro A B Ferraz ${ }^{2}$

\begin{abstract}
Introduction: Obesity is an important cause of cardiovascular disease, especially coronary artery disease. Severely obese patients are particularly prone to this risk. The coronary artery calcium (CAC) score is a strong predictor of coronary heart disease and provides incremental information beyond traditional risk factors. We sought to determine the prevalence of abnormally high CAC scores in the preoperative setting among patients undergoing bariatric surgery and to establish risk predictors for higher scores.

Methods: We performed an observational study of 202 patients free of known coronary artery disease who were referred for bariatric surgery. In each patient, the presence of CAC was detected with computed tomography, and coronary risk variables were either measured or determined via questionnaire.

Results: CAC was found in $14.4 \%$ of the overall population (26\% of male and $10.5 \%$ of female patients). Participants with altered CAC scores were older (mean age, 46.8 years). The variables positively associated with an altered CAC score were older age, male sex, type 2 diabetes, hypertension, and hypercholesterolemia. Multivariate-adjusted analysis showed that age $(\mathrm{OR}, 1.11 ; 95 \% \mathrm{Cl}, 1.06-1.17 ; \mathrm{p}=0.001)$, male sex $(\mathrm{OR}, 4.17 ; 95 \% \mathrm{Cl}, 1.52-11.47 ; \mathrm{p}=0.006)$, and hypercholesterolemia $(\mathrm{OR}, 6.21 ; 95 \% \mathrm{Cl}, 1.81-21.29 ; \mathrm{p}=0.004)$ were most closely related to the presence of $\mathrm{CAC}$.
\end{abstract}

Conclusion: Obese patients in the preoperative bariatric surgery setting have a high prevalence of abnormal CAC scores. Traditional risk factors play a important role in this scenario.

Keywords: Coronary artery calcium score; Coronary artery disease; Obesity; Bariatric surgery; Cardiovascular risk factors

\section{Introduction}

More than one-third (35.7\%) of United States adults are obese (CDC 2013). Obesity carries a high risk of comorbidities, including type 2 diabetes, systemic arterial hypertension, and dyslipidemia (De Sa et al. 2011; Pajecki et al. 2007). These are traditional risk factors for cardiovascular diseases, particularly for coronary heart disease (CHD) (Kopelman 2000). Evidence-based guidelines recommend that physicians assess their patients' baseline CHD risk and focus on primary preventative interventions (Expert Panel 2001).

Although coronary risk stratification is widely recommended, prediction models based on CHD risk factors are limited in their ability to discriminate individuals who will or will not develop CHD, leaving a large proportion of

\footnotetext{
* Correspondence: patricia_gadelha@yahoo.com.br

'Division of Endocrinology, Hospital das Clínicas, Universidade Federal de Pernambuco, Av. Prof. Moraes Rego, 1235-Cidade Universitária, Recife, PE CEP: 50670-901, Brazil

Full list of author information is available at the end of the article
}

patients classifiable as having "intermediate" risk (Diverse Populations Collaborative Group 2002). This category includes individuals with one or more risk factors that exceed desirable levels, including obesity (Greenland et al. 2001).

Given this uncertainty, recent guidelines have highlighted the potential use of anatomically based CHD assessment to refine this risk prediction (Greenland et al. 2004, 2010). One such approach uses computed tomography $(\mathrm{CT})$ to detect coronary artery calcium (CAC). The finding of CAC is related to an increased risk of incident CHD (Detrano et al. 2008) and is a proven objective, cost-effective, and independent prognostic tool in predicting this risk (Greenland et al. 2004; Taylor et al. 2005).

Obesity, especially visceral adiposity, has been associated with abnormally high CAC scores (Ho et al. 2009) and CAC progression (Kramer et al. 2009). However, little is known about CAC results in the specific population of

\section{实}


severely obese individuals for whom bariatric surgery is indicated. Therefore, the aims of the present study were to assess the prevalence of abnormally high CAC scores in the preoperative bariatric surgery setting and establish risk predictors for higher scores.

\section{Methods}

This study was carried out at the Universidade Federal de Pernambuco in Brazil and included all eligible patients who were referred for bariatric surgery from March 2012 to July 2013. A total of 202 patients met the following inclusion criteria: (i) body mass index (BMI) of $\geq 40$ or $\geq 35 \mathrm{~kg} / \mathrm{m}^{2}$ and one or more severe comorbidities according to the National Institutes of Health guidelines for bariatric surgery (Gastrointestinal surgery for severe obesity: National Institutes of Health Consensus Development Conference Statement 1992) and (ii) the absence of known coronary artery disease at the beginning of the study, including angina, myocardial infarction, and coronary revascularization. All patients gave their informed consent before participating in the present study. The institutional ethics committee (Ethic Committee of Health Sciences Center of Universidade Federal de Pernambuco) approved the study.

All study participants underwent questioning by a physician regarding the presence of any of the traditional risk factors, including a history of hypertension, type 2 diabetes mellitus, hypercholesterolemia, current medications, and current smoking. Fasting blood samples were collected to measure the levels of total cholesterol, low-density lipoprotein (LDL) cholesterol, high-density lipoprotein cholesterol, triglycerides, serum glucose, hemoglobin $\mathrm{A} 1 \mathrm{C}$ and insulin. Anthropometric measurements including height and weight were also collected, and BMI was calculated as weight $/$ height $^{2}\left(\mathrm{~kg} / \mathrm{m}^{2}\right)$.

Hypertension was defined as the current use of antihypertensive medication or known and untreated hypertension. Diabetes was defined as a fasting blood glucose level of $\geq 126 \mathrm{mg} / \mathrm{dL}$, a hemoglobin A1C level of $\geq 6.5 \%$, or the use of antidiabetic medications. Hypercholesterolemia was defined as a total cholesterol level of $>200 \mathrm{mg} / \mathrm{dL}$ or the current use of lipid-lowering therapy. Hypertriglyceridemia was defined as a triglyceride level of $>150 \mathrm{mg} / \mathrm{dL}$. Cigarette smoking was considered to be present if the patient was a smoker at the time of the survey.

All patients underwent CAC scoring with a 128-row multidetector CT scanner (Siemens Somatom Definition AS, Siemens Medical Systems, Erlangen, Germany). Fortyeight contiguous CT slices were obtained at 3-mm intervals beginning $1 \mathrm{~cm}$ below the carina and progressing caudally to include the entire coronary tree. The image acquisition was triggered to $60 \%$ to $80 \%$ of the electrocardiographic R-R interval. Scans were interpreted by an experienced radiologist using the Agatston scoring method (Agatston et al. 1990). A focus of CAC was defined as the presence of three or more contiguous pixels with $>130$ Hounsfield units. The total CAC score was calculated as the sum of the individual scores of the three major epicardial coronary arteries. A scan was considered positive for $\mathrm{CAC}$ when the total CAC score was $>0$ (Figure 1 ).

Baseline characteristics in terms of the presence of CAC were computed as means or percents, and differences were tested using $t$ tests or chi-square statistics, respectively. Multiple logistic regression after adjustment of univariate variables was conducted for age, sex, and hypercholesterolemia. Odds ratios (ORs) and 95\%

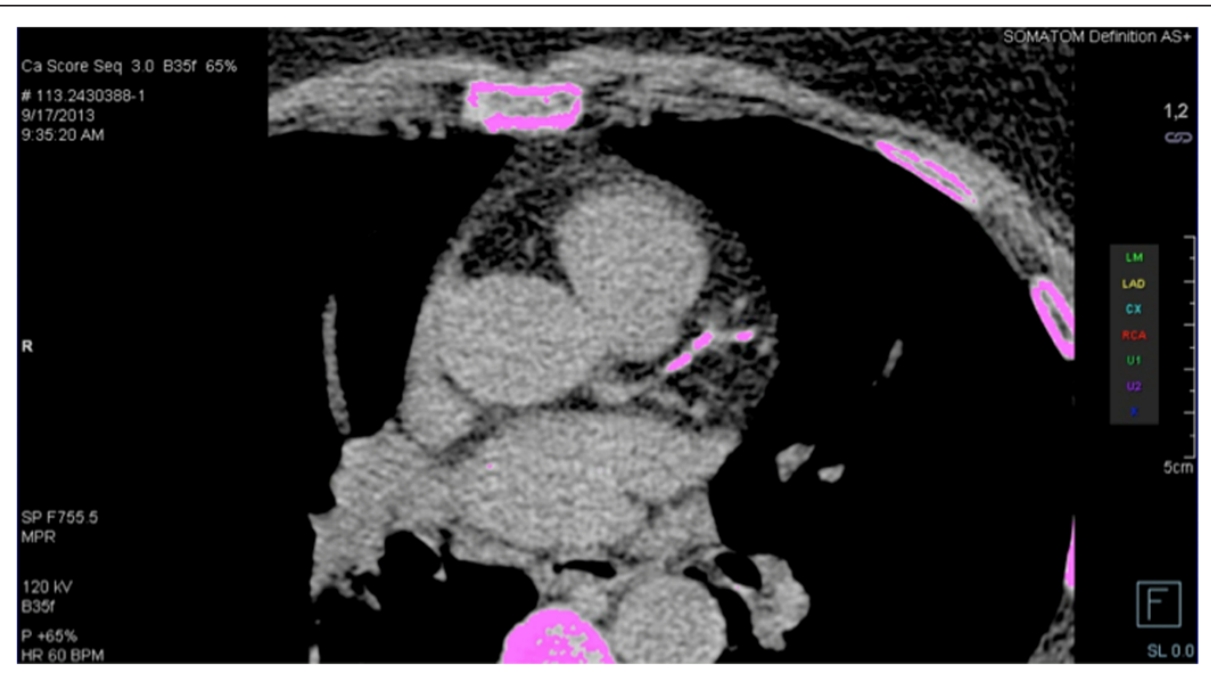

Figure 1 Coronary artery calcification (CAC) of the left anterior descending coronary artery. Workstation screen displaying a noncontrast enhanced axial image postprocessed with a calcium scoring preset: areas > $130 \mathrm{HU}$ are coloured. A region of interest has been manually drawn, encircling areas at the main trunk and the distal segment of the left anterior descending coronary artery. 
confidence intervals (CIs) were approximated. All statistical analyses were performed with a statistical software package (SPSS 18.0; SPSS Inc., Chicago, IL), and a $\mathrm{p}$ value of $<0.05$ was considered statistically significant.

\section{Results}

Among the 202 total patients, 152 (75.2\%) were female, and the mean age of the population was 36.3 years. The mean BMI was $40.5 \mathrm{~kg} / \mathrm{m}^{2}$. Hypertension, type 2 diabetes mellitus, hypercholesterolemia, hypertriglyceridemia, and current smoking were present in $98(48.5 \%), 40$ (19.8\%), 109 (54.0\%), 89 (44.1\%), and 13 (6.4\%) patients, respectively (Table 1).

CAC was present in $14.4 \%(n=29)$ of the overall population (26\% of male and $10.5 \%$ of female patients). The mean age of the patients with detectable CAC was 46.8 years. Of note, the presence of CAC did not lead to any clinical perioperative cardiovascular adverse outcome.

Univariate analyses were performed to identify factors that affect the presence of CAC. The presence of CAC was associated with male sex, age, diabetes, hypertension, and hypercholesterolemia (all p < 0.001) (Table 2).

Multivariate analysis was then performed including variables that reached statistical significance in the univariate analyses. The presence of CAC was associated with male sex (OR, 4.17; 95\% CI, 1.52-11.47; $\mathrm{p}=0.006$ ), older age (OR, 1.11; 95\% CI, 1.06-1.17; $\mathrm{p}=0.001)$, and hypercholesterolemia (OR, 6.21; 95\% CI, 1.81-21.29; $\mathrm{p}=$ 0.004) (Table 3).

\section{Discussion}

CAC represents a measure of the overall cardiac plaque burden (Budoff et al. 2006) and is a proven independent predictor of cardiovascular events (Detrano et al. 2008; Taylor et al. 2005). Previous studies have demonstrated an association between obesity and the presence of CAC. In the Multi-Ethnic Study of Atherosclerosis (MESA), Burke et al. (2008) demonstrated that obesity was associated with a 1.2-fold greater prevalence of CAC. However,

Table 1 Demographic and biochemical characteristics of participants

\begin{tabular}{lc}
\hline Variables & $\mathbf{N}=\mathbf{2 0 2}$ \\
\hline Age (yrs, mean \pm SD) & $36.3 \pm 10.3$ \\
Female sex, $n(\%)$ & $152(75.2 \%)$ \\
BMl (kg/m², mean \pm SD) & $40.5 \pm 4.3$ \\
Diabetes mellitus, $n$ (\%) & $40(19.8 \%)$ \\
Hypertension, $n(\%)$ & $98(48.5 \%)$ \\
Current smoker, $n(\%)$ & $13(6.4 \%)$ \\
Hypertriglyceridemia, $n(\%)$ & $89(44.1 \%)$ \\
Hypercholesterolemia, $n(\%)$ & $109(54.0 \%)$ \\
\hline
\end{tabular}

$B M I$ body mass index, $S D$ standard deviation.
Table 2 Univariate analysis of variables influencing the presence of CAC

\begin{tabular}{lccc}
\hline Variables & \multicolumn{2}{c}{ CAC } & P value \\
\cline { 2 - 3 } & $\mathbf{0 ( \mathbf { n } = \mathbf { 1 7 3 } )}$ & $>\mathbf{0}(\mathbf{n}=\mathbf{2 9 )}$ & \\
\hline Male & $37(21.4 \%)$ & $13(44.8 \%)$ & 0.007 \\
Mean Age (SD) & $34.3(8.9)$ & $46.8(11.9)$ & $<0.001$ \\
Mean BMI (SD) & $40.4(4.4)$ & $41.2(3.8)$ & 0.358 \\
Diabetes & $27(15.6 \%)$ & $13(44.8 \%)$ & $<0.001$ \\
Hypertension & $77(44.5 \%)$ & $21(72.4 \%)$ & 0.005 \\
Current smoking & $11(6.4 \%)$ & $2(6.9 \%)$ & $>0.999$ \\
Hypertriglyceridemia & $76(43.9 \%)$ & $13(44.8 \%)$ & 0.928 \\
Hypercholesterolemia & $84(48.6 \%)$ & $25(86.2 \%)$ & $<0.001$ \\
\hline
\end{tabular}

$C A C$ coronary artery calcification, $B M I$ body mass index, $S D$ standard deviation.

there was a lack of data regarding the CAC score in a specific population of preoperative severely obese patients undergoing bariatric surgery.

The present study showed a prevalence of altered CAC scores in our population of $14.4 \%, 26 \%$ of males and $10.5 \%$ of females. Taylor et al. (2005) reported altered CAC scores in $22.4 \%$ of men and $7.9 \%$ of women in the Prospective Army Coronary Calcium Project (PACC), which analyzed 2000 participants with a mean age of 43 years. Tota-Maharaj et al. (2012) reported a prevalence of high CAC scores in 5\% of their study subgroup, which had a mean age of 40 years. Considering that our study population had a lower mean age than that of other studies (36.3 years) and we still found a higher prevalence of abnormal CAC scores than that found in studies of nonobese subjects, we can assume that severe obesity is an important contributor to vascular calcification.

Our results also showed that age and male sex are associated with the presence of CAC. Previous studies have reported that older age is a main risk factor of higher CAC scores (Tota-Maharaj et al. 2012; McClelland et al. 2006; Budoff et al. 2007). McClelland et al. (2006) reported that the relationship between the probability of any detectable calcium and age is linear. The prevalence of CAC was higher in male patients, with 4-fold greater risk of a CAC score of $>0$. This finding is also compatible with those of previous studies (Taylor et al. 2005; McClelland et al. 2006; Loria et al. 2007).

Table 3 Multivariate analysis of presence of CAC

\begin{tabular}{lccc}
\hline Parameter & OR & $\mathbf{9 5 \% ~ C l}$ & $P$ value \\
\hline Age & 1.11 & $1.06-1.17$ & 0.001 \\
Male gender & 4.17 & $1.52-11.47$ & 0.006 \\
Hypercholesterolemia & 6.21 & $1.81-21.29$ & 0.004 \\
\hline
\end{tabular}

$C A C$ coronary artery calcification, $O R$ odds ratio, $\mathrm{Cl}$ confidence interval. 
Type 2 diabetes mellitus and hypertension were associated with high CAC scores in our study. Both are known traditional risk factors and have been associated with the presence of CAC in previous reports (Budoff et al. 2007; Loria et al. 2007; Hoff et al. 2003). Hypercholesterolemia was the strongest single variable associated with high CAC scores. The presence of hypercholesterolemia was associated with a 6-fold risk of having CAC. This finding can be understood in view of the fact that obese patients have an increased concentration of small, dense LDL particles. These LDL particles are more prone to oxidation and can move through endothelial fenestrations and enter the subendothelial space, where inflammation and transformation into plaque can occur (van Gaal et al. 2006).

The lack of a significant difference in CAC scores between smokers and nonsmokers, a finding that is in disagreement with previous studies (Loria et al. 2007; Budoff et al. 2009), could be due to the low prevalence of smoking in our population. A larger sample size would be required to identify a statistically significant difference.

The results of our study should be interpreted in the context of some limitations. First, it was a crosssectional study and thus did not provide long-term outcomes data for the included patients. Second, some variables were measured while others were self-reported, and the potential of under-reporting might be considered. Finally, the patients were self-referred subjects; this may have caused bias because the study population may not represent the whole population of severely obese patients, who, in many developed countries, do not have access to medical treatment for obesity and its consequences.

\section{Conclusion}

This study provides valuable information regarding CAC scores in severely obese patients, which may help physicians to encourage patients to achieve changes in modifiable risk factors and thus prevent, or at least delay, coronary artery calcification.

\section{Abbreviations}

BMI: Body mass index; CAC: Coronary artery calcium; Cl: Confidence intervals; CT: Coronary tomography; CHD: Coronary heart disease; LDL: Low-density lipoprotein; MESA: Multi-Ethnic Study of Atherosclerosis; OR: Odds ratio; PACC: Prospective Army Coronary Calcium Project.

\section{Competing interests}

The authors declare that they have no competing interest.

\section{Authors' contributions}

PG acquired and analyzed the data and drafted the manuscript. AF substantially contributed to data collection and manuscript revision. ML examined each participant's scan. JC and FM reviewed the data and manuscript and provided critical intellectual input. All authors read and approved the final manuscript.

\section{Author details}

'Division of Endocrinology, Hospital das Clínicas, Universidade Federal de Pernambuco, Av. Prof. Moraes Rego, 1235-Cidade Universitária, Recife, PE CEP: 50670-901, Brazil. ²Division of Surgery, Hospital das Clínicas,

Universidade Federal de Pernambuco, Av. Prof. Moraes Rego, 1235-Cidade Universitária, Recife, PE CEP: 50670-901, Brazil. ${ }^{3}$ Division of Radiology, Real Hospital Português, Av. Agamenon Magalhães, № 4760, Recife, PE CEP: 52010-902, Brazil.

Received: 10 April 2014 Accepted: 15 April 2014

Published: 22 April 2014

\section{References}

Agatston AS, Janowitz FWR, Hildner FJ, Zusmer NR, Viamonte M, Detrano R (1990) Quantification of coronary artery calcium using ultrafast computed tomography. J Am Coll Cardiol 15(4):827-832

Budoff MJ, Achenbach S, Blumenthal RS, Carr JJ, Goldin JG, Greenland P, Guerci AD, Lima JAC, Rader DJ, Rubin GD, Shaw L, Wiegers SE (2006) Assessment of coronary artery disease by cardiac computed tomography: a scientific statement from the American Heart Association Committee on Cardiovascular Imaging and Intervention, Council on Cardiovascular Radiology and Intervention, and Committee on Cardiac Imaging, Council on Clinical Cardiology. Circulation 114(16):1761-1791

Budoff MJ, Shaw LJ, Liu ST, Weinstein SR, Mosler TP, Tseng PH, Flores FR, Callister TQ, Raggi P, Berman DS (2007) Long-term prognosis associated with coronary calcification: observations from a registry of 25,253 patients. J Am Coll Cardiol 49(18):1860-1870

Budoff MJ, McClelland RL, Nasir K, Greenland P, Kronmal RA, Kondos GT, Shea S, Lima JACL, Blumenthal S (2009) Cardiovascular events with absent or minimal coronary calcification: the Multi-Ethnic Study of Atherosclerosis (MESA). Am Heart J 158(4):554-561

Burke GL, Bertoni AG, Shea S, Tracy R, Watson KE, Blumenthal RS, Chung HCM (2008) The impact of obesity on cardiovascular disease risk factors and subclinical vascular disease. Arch Intern Med 168(9):928-935

CDC (2013) National Center for Health Statistics., Available from http://www.cdc. gov/obesity/data/adult.html. Acessed 20 October 2013

De Sa VCT, Ferraz AA, Campos JM, Ramos AC, Araujo JGC, Ferraz EM (2011) Gastric bypass in the treatment of type 2 diabetes in patients with a BMl of 30 to $35 \mathrm{~kg} / \mathrm{m} 2$. Obes Surg 21(3):283-287

Detrano R, Guerci AD, Carr JJ, Bild DE, Burke G, Folsom AR, Liu K, Shea S, Azko M, Bluemke DA, O'Leary DH, Tracy R, Watson K, Wong ND, Kronmal RA (2008) Coronary calcium as a predictor of coronary events in four racial or ethnic groups. N Engl J Med 358(13):1336-1345

Diverse Populations Collaborative Group (2002) Prediction of mortality from coronary heart disease among diverse populations: is there a common predictive function? Heart 88(3):222-228

Expert Panel on Detection, Evaluation, and Treatment of High Blood Cholesterol in Adults (2001) Executive summary of the third report of the National Cholesterol Education Program (NCEP) expert panel on detection, evaluation, and treatment of high blood cholest. JAMA 285:2486-2497

Greenland P, Smith SC, Grundy SM (2001) Improving coronary Heart disease risk assessment in asymptomatic people: role of traditional Risk factors and noninvasive cardiovascular tests. Circulation 104(15):1863-1867

Greenland P, Labree L, Azen SP, Doherty TM (2004) Coronary artery calcium score combined with Framingham score for risk prediction in asymptomatic individuals. JAMA 291(2):210-215

Greenland P, Alpert JS, Beller GA, Benjamin EJ, Budoff MJ, Fayad ZA, Foster E, Hlatky MA, Hodgson J, McB KFG, Lauer MS, Shaw LJ, Smith SC, Taylor AJ, Weintraub WS, Wenger NK (2010) 2010 ACCF/AHA guideline for assessment of cardiovascular risk in asymptomatic adults: a report of the American College of Cardiology Foundation/American Heart Association Task Force on Practice Guidelines. J Am Coll Cardiol 56(25):e50-e103

Ho JS, Cannaday JJ, Barlow CE, Willis B, Haskell WL, Fitzgerald SJ (2009) Comparative relation of general, central, and visceral adiposity measures for coronary artery calcium in subjects without previous coronary events. Am J Cardiol 104(7):943-946

Hoff JA, Quinn L, Sevrukov A, Lipton RB, Daviglus M, Garside DB, Ajmere NK, Gandhi S, Kondos GT (2003) The prevalence of coronary arterycalcium among diabetic individuals without known coronary artery disease. J Am Coll Cardiol 41(6):1008-1012

Kopelman PG (2000) Obesity as a medical problem. Nature 404(6778):635-643 
Kramer CK, von Mühlen D, Gross JL, Barrett-Connor E (2009) A prospective study of abdominal obesity and coronary artery calcium progression in older adults. J Clin Endocrinol Metab 94(12):5039-5044

Loria CM, Liu K, Lewis CE, Hulley SB, Sidney S, Schreiner PJ, Williams OD, Bild DE, Detrano R (2007) Early adult risk factor levels and subsequent coronary artery calcification: the CARDIA Study. J Am Coll Cardiol 49(20):2013-2020

McClelland RL, Chung H, Detrano R, Post W, Kronmal R (2006) Distribution of coronary artery calcium by race, gender, and age: results from the Multi-Ethnic Study of Atherosclerosis (MESA). Circulation 113(1):30-37

Gastrointestinal surgery for severe obesity (1992) National Institutes of Health Consensus Development Conference Statement. Am I Clin Nutr 55(2 Suppl):615S-619S

Pajecki D, Dalcanalle L, de Oliveira CPM S, Zilberstein B, Halpern A, Garrido AB, Cecconello I (2007) Follow-up of Roux-en-Y gastric bypass patients at 5 or more years postoperatively. Obes Surg 17(5):601-607

Taylor AJ, Bindeman J, Feuerstein I, Cao F, Brazaitis M, O'Malley PG (2005) Coronary calcium independently predicts incident premature coronary heart disease over measured cardiovascular risk factors: mean three-year outcomes in the Prospective Army Coronary Calcium (PACC) project. J Am Coll Cardiol 46(5):807-814

Tota-Maharaj R, Blaha MJ, Rivera JJ, Henry TS, Choi E-K, Chang S-A, Yoon YE, Chun EJ, Choi S, Blumental RS, Chang H, Nasir K (2012) Differences in coronary plaque composition with aging measured by coronary computed tomography angiography. Int J Cardiol 158(2):240-245

Van Gaal LF, Mertens IL, De Block CE (2006) Mechanisms linking obesity with cardiovascular disease. Nature 444(7121):875-880

doi:10.1186/2193-1801-3-199

Cite this article as: Gadelha et al: Altered coronary artery calcium scores before bariatric surgery. SpringerPlus 2014 3:199.

\section{Submit your manuscript to a SpringerOpen ${ }^{\circ}$} journal and benefit from:

- Convenient online submission

- Rigorous peer review

- Immediate publication on acceptance

- Open access: articles freely available online

- High visibility within the field

- Retaining the copyright to your article

Submit your next manuscript at $\gg$ springeropen.com 